Session 2532

\title{
Using Self-Evaluation and Student Generated Portfolios for Assessment of Student Learning and Course Effectiveness
}

\author{
Jeffrey A. Jalkio \\ Department of Engineering \\ University of St. Thomas
}

\begin{abstract}
$\underline{\text { Abstract }}$
One advantage of having clearly articulated learning objectives for courses is that students can focus on these objectives to unify course material. Unfortunately, students often ignore the stated course objectives and focus their attention on the specific work required to earn good grades from the instructor. This paper presents a technique for shifting the student focus from the external validation of course grades to a self-evaluation of accomplishment of course learning objectives. Preliminary results from a classroom trial of this technique will be presented.
\end{abstract}

This approach aims to tie the course grade directly to the student's self-assessment. At the beginning of the semester, students are given a detailed list of course learning objectives and a grading rubric that relates letter grades to demonstrated levels of accomplishment of these objectives. During the course of the semester assignments are collected and graded to provide formative feedback to the students. At midterm and at the end of the semester, students are required to give the instructor a portfolio of work demonstrating accomplishment of the learning objectives and a summary evaluation specifying the letter grade earned and how the attached portfolio supports their self-assessment. The portfolio primarily includes graded examinations and reports, but can also include other material selected by the student. Summative feedback for the course is based directly on the student self-assessment.

In addition to focusing the students' attention on course learning objectives, this approach has benefits for program assessment. The portfolio submitted by the student is documentation of successful accomplishment of course objectives and the student self-assessment provides useful information to the instructor on the efficacy of instructional methods and the adequacy of graded work in providing feedback to the student.

$\underline{\text { Introduction }}$

The grading experiment described in this paper arose in response to the convergence of three separate issues that confront all engineering faculty. First, how do we assign grades that provide accurate feedback to our students on their overall academic progress in achieving course objectives. Second, how do we assess the efficacy of our instruction so that we can improve our

Proceedings of the 2002 American Society for Engineering Education Annual Conference and Exposition Copyright (C) 2002, American Society for Engineering Education 
classes and document accomplishment of objectives for accreditation purposes. Third, how do we motivate student reflection on the material beyond memorization of formulae to the integration of math, science, and engineering topics into their mental toolbox.

The issue of grading has been addressed in several ways and is important because students often ignore the stated course objectives and focus their attention on the specific work required to earn a desired grade from the instructor. Traditional norm-referenced grading techniques reinforce this tendency by suggesting that the students are graded on how well they perform on tests compared to their classmates ${ }^{1}$. Criterion-referenced grading rubrics used in engineering courses typically assign grades based on a weighted percentage of points scored in exams, homework, and other graded assignments ${ }^{2}$. However, if a course has ten learning objectives that receive equal point weighting, a student can theoretically score $90 \%$ of points without demonstrating any

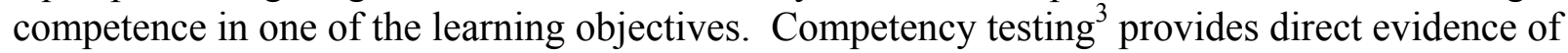
the accomplishment of learning objectives, but typically only on a pass/fail basis for each learning objective. Our goal was to develop a grading system that would allow us to assign grades based on demonstrated mastery of learning objectives. Since the successful completion of many laboratory experiments and exam questions require the attainment of several learning objectives, it is difficult to determine the demonstrated level of performance in most cases. As a result, this rubric would result in prohibitive levels of effort on the part of an instructor if the instructor had to determine the level of mastery demonstrated by each student.

The second issue, that of course level assessment, has been discussed in the literature considerably in recent years. It is critical for the formation of any meaningful plan for the continuous improvement of our courses, as well as being a crucial portion of the program assessment required by ABET. Many assessment instruments have been discussed in the literature ${ }^{4}$ and their advantages and disadvantages have been weighed. A number of schools have considered student portfolios as a tool for documenting student achievement of learning objectives and have described systems for effectively managing student portfolios ${ }^{5}$. Typical concerns raised regarding the use of student portfolios include the time required for faculty evaluation of the portfolio, storage resources required if the portfolio is maintained by the institution, and lack of compliance if the portfolio is maintained by the student.

The third issue was seeking student ownership of the learning process. It is well known that students often focus on grades to the exclusion of learning the material ${ }^{6}$ As a result, students often learn the material in a course well enough to obtain the desired grade and promptly forget the material since it is not linked to anything else they have learned and they don't understand why it is important. We wish to design a system that shifts the student's motivation away from the grade received and towards the building of a knowledge and skill base that will prove useful in the engineering profession. One way to move towards this goal is through student selfassessment of their work ${ }^{7}$. This has been shown to promote reflection on the learning process and a shift in motivation towards accomplishing learning objectives. Unfortunately, accurate self-assessment requires maturity and expertise and most studies of self-assessment reveal biases $^{8}$. Below average performers tend to overestimate their skills while above average performers tend to underestimate them. 
We believe that these disadvantages of self-assessment can be overcome if we clearly identify the differing roles of formative and summative evaluation. In formative evaluation, we seek to provide feedback to the student so that they can improve their performance. In most engineering subjects, self-evaluation is inappropriate for this purpose (although self and peer evaluation have proven useful in assessing attitudinal objectives ${ }^{9}$ ). However, in summative evaluation such as overall course grading, the objective is to provide overall feedback on the student's performance after correction. We believe that the student can provide this evaluation based on data from formative evaluations.

This is the basis of our experimental grading system. We provide the students with a list of learning objectives and a grading rubric at the beginning of the semester. During the course of the semester, the student receives formative evaluation of lab reports, quizzes, homework assignments and examinations as is usually done in an engineering course. The students then prepare a self-assessment of their demonstrated mastery of each learning objective and present it at the end of the semester together with their portfolio of supporting documentation. This technique appears to support all three of the aforementioned objectives.

\section{Method Used}

This methodology was tested in a new sophomore level course in digital design being offered for the first time this fall as part of a new electrical engineering curriculum. A set of learning objectives were developed for this course as part of our standard curriculum development process. These learning objectives are shown below:

\section{Course Learning Objectives}

1. Understanding of the principles of combinational and sequential logic design as demonstrated in quizzes and tests.

2. Ability to apply those principles to the design and analysis of practical digital systems as demonstrated in laboratory experiments and student design projects.

3. Ability to use software tools and lab instruments to design, simulate, implement, test and document digital systems using standard and programmable components.

Although suitable for most purposes, we believed that they were not detailed enough to be useful for sophomores to accurately measure their accomplishment, so a much more detailed list of learning objectives was generated as shown below: 


\section{Detailed Course Learning Objectives}

\section{$\underline{\text { Skills }}$}

Upon successful completion of the course, the student will be able to:

1. Use mixed signal scopes for debugging digital circuits,

2. Translate numbers between binary, decimal and hexadecimal codes,

3. Perform arithmetic on binary, octal, and hexadecimal numbers,

4. Convert between schematics, truth tables, and Boolean equations,

5. Determine equality of Boolean expressions,

6. Simplify Boolean expressions,

7. Design combinational logic circuits to accomplish specified tasks,

8. Design sequential logic circuits to accomplish specified tasks,

9. Use ABEL to synthesize combinational and sequential circuits,

10. Document digital designs sufficiently for others to use them,

11. Verify the performance of a digital design using software simulation tools, 12. Analyze circuits to detect and remove hazards,

13. Use VHDL for simulation and synthesis of logic circuits.

Knowledge

Upon successful completion of the course, the student will be able to explain:

1. How binary codes are used to represent characters, pictures, and numbers,

2. The advantages of $2 \mathrm{~s}$ complement, binary coded decimal, and gray codes,

3. Boolean algebra and logic gate behavior,

4. Function and application of common MSI components,

5. Flip Flop construction and behavior in terms of combinational logic,

6. Metastability and how synchronizers work,

7. Architectures, capabilities and prices of current programmable devices,

8. Implementation issues including fanout, noise, power, and speed.

\section{Attitudes}

During the course, the student must at all times exhibit:

1. Concern for the safety of themselves and others,

2. Efficient use of time and resources,

3. Courtesy to classmates, faculty and staff,

4. Personal integrity,

5. Desire for clear communication,

6. Desire to achieve objectives. 
These objectives are categorized as knowledge, skills or attitudinal based on Bloom's taxonomy. It should be noted that each of the skill and knowledge objectives is clear and measurable. We are still not satisfied with the clarity of the attitudinal objectives, but decided to keep them in the list to determine how the students would self assess these items.

Next we set out to develop a grading rubric based on demonstrated accomplishment of learning objectives. We believed that a passing grade should correspond to a minimal acceptable accomplishment of all objectives, since we wish to know that every graduate of our program has accomplished all learning objectives. This led to the problem of defining A and B level performance, since if a $\mathrm{C}$ indicates that a student has accomplished all objectives, what could an A mean. Our conclusion was that we would differentiate between demonstrated levels of mastery. C level performance on a learning objective was demonstrated by a student just barely able to perform the task, perhaps with some assistance. B level performance was demonstrated by independently performing the task with some proficiency, but could theoretically be accomplished through rote memorization. To demonstrate accomplishment of an objective at the A level, a student must apply the skill or knowledge to problems or situations beyond those covered in class, showing a deeper understanding of the material beyond mere memorization. The resulting grading rubric is shown below:

\section{$\underline{\text { Grading Rubric }}$}

A: Demonstrates through tangible evidence a mastery of course material to the extent that the student can apply the knowledge gained in the class to solve problems in the subject area beyond those solved in class.

B: Demonstrates through tangible evidence an accomplishment of al learning objectives with a sufficient mastery to be able to solve typical problems encountered by engineers in the subject matter of the course. However, the student has not demonstrated the ability to apply the knowledge gained in the course to problems beyond those solved in class

C: Demonstrates through tangible evidence an accomplishment of all learning objectives at a minimal level that shows they might work in the field under appropriate supervision, but did not demonstrate sufficient mastery of the subject for the instructor to be confident of the student's ability to solve problems independently.

D: Does not demonstrate accomplishment of all learning objectives specified in the syllabus. However, student shows evidence that they learned enough from the course that it should count for college credit. This grade indicates that the student has not demonstrated mastery of the material at the level needed to continue in classes that have this course as a prerequisite.

F: Does not provide evidence of sufficient learning to receive college credit for this course. 
At the beginning of the semester, the students received both the learning objectives and the grading rubric with the requirement that to receive a passing grade, they would need to document the accomplishment of all objectives at the desired grade level. This documentation would be required for mid-term and final grading. It was suggested that it would be wise to keep their records up to date on at least weekly and the students were given examples of an acceptable level of documentation. During the course of the semester, the instructor would grade weekly quizzes, homework, lab reports, and examinations as in a typical class. Periodically, the students would be reminded of the need to record the accomplishment of learning objectives and opportunities to demonstrate mastery would be pointed out to them. Similarly, comments or decisions made in lab that demonstrated the application of the subject matter beyond what was presented in class were pointed out for inclusion in the documentation.

At mid-semester, students submitted their self-assessment reports with a portfolio of supporting documentation. This documentation was to consist primarily of graded assignments and exams but the students were permitted to include other material to support claims of A or B level work. These self-assessment reports were two to five pages in length and identify evidence demonstrating the accomplishment of all course learning objectives. As an example, for skill 7 (combinational circuit design), one student wrote, "This is demonstrated at a B level in exam 1 question 6, but at an A level in lab 4". Not all of the students had fully understood the assessment assignment and only seven of nine reported recommended grades. Since the instructor had been tracking the graded work during the semester it was possible to compare the self-assessments with the grade that would traditionally be assigned. Those students who had recommended a grade assigned essentially the same grades as the instructor traditionally would have assigned. Clarifications were made on the format of the self-assessment based on the errors that occurred at midterm and the process was repeated when final grades were due. Although the sample size was too small to be statistically significant, 8 of 9 students assigned themselves the same grade that the instructor would have assigned independently.

\section{$\underline{\text { Results }}$}

Several concerns were raised at the beginning of this experiment. First, the use of portfolios often entails a great deal of additional work on the part of the faculty. In this case, there was some additional work before the semester began to develop detailed learning objectives and a grading rubric. There was also some additional work required to review the two self-assessment reports submitted by the students and this work will scale linearly with the number of students in the class. These were each equivalent to one written assignment, so the total additional workload was minimal. In fact, if over time, we gain confidence in this methodology, the extra work involved might be negated by the decreased work required for grading.

Additional work is clearly required of the student and this may seem onerous for students already taking a heavy load of engineering courses. However, we should consider what additional work we are requiring. We are asking the students to keep documentation of their work, update records on a regular weekly basis, reflect on what they have learned and how they 
have demonstrated mastery of new skills, and plan how they will accomplish goals. These are not additional burdens on our students but rather habits that they must develop for success in engineering. Student comments on the self-assessment process indicate that although they don't welcome the extra work, most found the process useful and felt that they had a better understanding of what they had learned because of it.

Based on my experience this semester, it is clear that the grading rubric needs to be improved perhaps by providing examples of $\mathrm{A}, \mathrm{B}$, and $\mathrm{C}$ level performance.

\section{Acknowledgments}

I would like to thank my students in ENGR 230, Clare Carron, Aaron Boesch, Isaac Schwoch, Ryan Nelson, Greg Ogin, Mike Preiner, Nick Schleder, Jason Larson and Joe Dickson for taking part in this project.

\section{$\underline{\text { References }}$}

${ }^{1}$ Wankat, P. and Oreovicz, F., "Teaching-hit your mark", ASEE Prism, Nov 2001.

${ }^{2}$ Guskey, T. R., "Helping standards make the grade", Educational Leadership, vol 59, No. 1, Sept 2001, pp20-27.

${ }^{3}$ Hochstein, J.I. and Perry, E. H., “Direct Competency Testing - Is It For You?", Proceedings of the 1999 ASEE Annual Conference.

${ }^{4}$ Angelo, T.A. and Cross, K. P., Classroom Assessment Techniques - A Handbook for College Teachers, $2^{\text {nd }}$ ed., Jossey-Bass, San Francisco,1993.

${ }^{5}$ Handley, M. K., "Portfolio Assessment as a Measure of Student and Program Success", Proceedings of the 1999 ASEE Annual Conference.

${ }^{6}$ Reeves, D. B., "Standards Make a Difference: The Influence of Standards on Classroom Assessment", NASSP Bulletin vol. 85, no. 621 Jan 2001, pp. 2-65.

${ }^{7}$ Petit, M. and Zawojewski, J. S., "Teachers adn Students Learning Together about Assessing Problem Solving”, Methematics Teacher, vol.90, Sept 1997, pp. 472-477.

${ }^{8}$ Falchikov, N. and Boud, D. "Student Self-Assessment in Higher Education: A Meta-Analysis", Review of Educational Research, vol. 59, pp.395-430.

${ }^{9}$ Gopinath, C., “Alternatives to Instructor Assessment of Class Participation”, Journal of Education for Business, vol. 75, no 1, Sept 1999, pp 10-14.

\section{JEFFREY A. JALKIO}

Jeff Jalkio received his PhD in Electrical Engineering from the University of Minnesota and worked for several years in industry in the fields of optical sensor design and process control. In 1984, he co-founded CyberOptics Corporation with Dr. Steve Case, where he headed research and development. In 1997 he returned to academia, joining the engineering faculty of the University of St. Thomas where he teaches courses in electronics, mechatronics, controls, and design. 